\title{
Atypical chest pain: Needles in a haystack
}

\author{
J M Jansen van Vuuren, ${ }^{1} \mathrm{MB}$ BCh; S Pillay, ${ }^{2} \mathrm{MB}$ ChB, FCP (SA), MMed; K Ramchandre ${ }^{2}$ MB ChB, FCP (SA) \\ ${ }^{1}$ Medical Intern, Pietermaritzburg Hospital Complex, South Africa \\ ${ }^{2}$ Department of Internal Medicine, Edendale Hospital, Pietermaritzburg, South Africa
}

Corresponding author: J M Jansen van Vuuren (juanjvanvuuren@gmail.com)

\begin{abstract}
A 20 -year-old man presented with a 6-month history of intermittent chest pain. Initial imaging demonstrated approximately 15 sewing needles lodged in his myocardium, predominantly in the left ventricle. The patient has been referred to cardiothoracic surgery for further management. His progress will be monitored closely.
\end{abstract}

S Afr Med J 2016;106(11):1090-1091. DOI:10.7196/SAMJ.2016.v106i11.11057

\section{Case report}

A 20 -year-old previously healthy man, with no known comorbidities, presented to the triage desk at Edendale Hospital, Pietermaritzburg, South Africa (SA). He complained of a 6-month history of relapsing and remitting, spontaneous-onset chest pain lasting up to 3 days, after which he would experience no symptoms for several weeks at a time. The character of the pain was described as sharp, localised to his left subcostal margin and associated with pain in the tip of the left shoulder and left-hand paraesthesiae (without a specific dermatomal pattern).

At about the time of the onset of these symptoms, the patient had experienced a brief psychotic disorder, reporting 2 weeks of visual and auditory hallucinations, grandiose delusions and disorganised speech and behaviour, which had interfered with his everyday life. This was his first and only such episode. Sober habits were reported.

The patient had visited his local traditional healer, and reported receiving herbal remedies but no form of surgical intervention.

Examination of the patient revealed vital signs that were within normal limits. He was in no form of distress and appeared comfortable, walking without assistance. General examination revealed no abnormalities except for four minute scars, measuring approximately $1 \mathrm{~mm}$ in length, which could be seen on his anterior chest, $2.5 \mathrm{~cm}$ superior and $1 \mathrm{~cm}$ left lateral to the xiphisternum. A prominent pulsation could be seen parasternally within the 5 th intercostal space on the left, which was easily palpable. No added heart sounds or murmurs were audible. Thorough clinical examination revealed no further abnormalities.

Chest radiographs (posteroanterior and lateral views, Fig. 1, $\mathrm{A}$ and $\mathrm{B}$ ) showed approximately 15 radio-opaque foreign bodies lodged in the mediastinum, localised within what appeared to be the myocardium. Closer inspection of the radiographs showed these to be needles of the type used for sewing.

An electrocardiogram showed a minor interference pattern but no ischaemic changes, and the results of blood tests were all within normal limits.

An echocardiogram confirmed the presence of foreign bodies in the myocardium (Fig. 2). There was no evidence of valvular defects or pericardial abnormalities, but the needles could be seen moving freely within the myocardium with each contraction. Ultrasound Doppler imaging showed some blood flow into a small space created by one of the needles, indicating possible communication with the ventricular cavity.

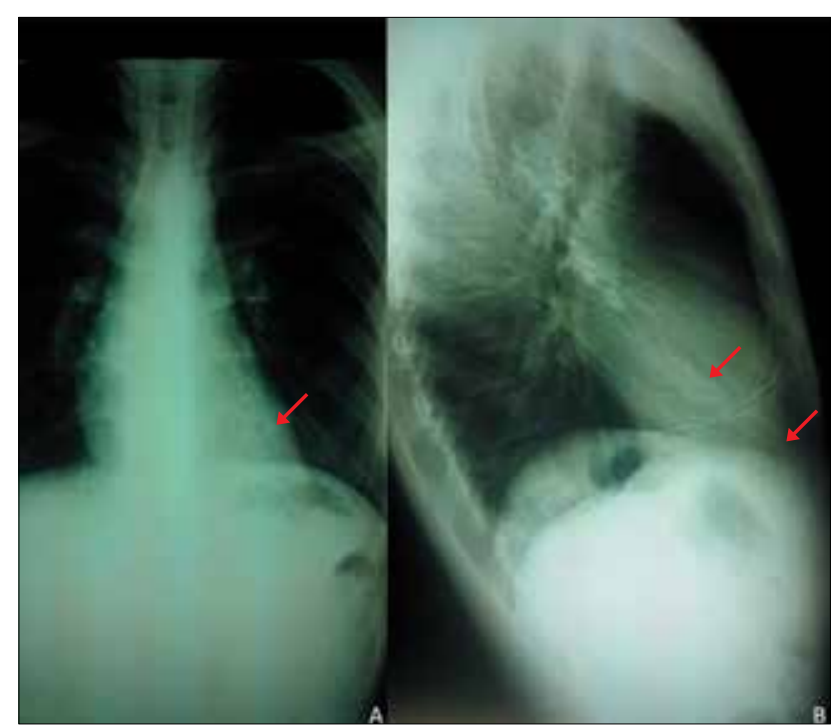

Fig. 1. Posteroanterior (A) and lateral (B) chest radiographs. Note radioopaque foreign bodies (arrows).

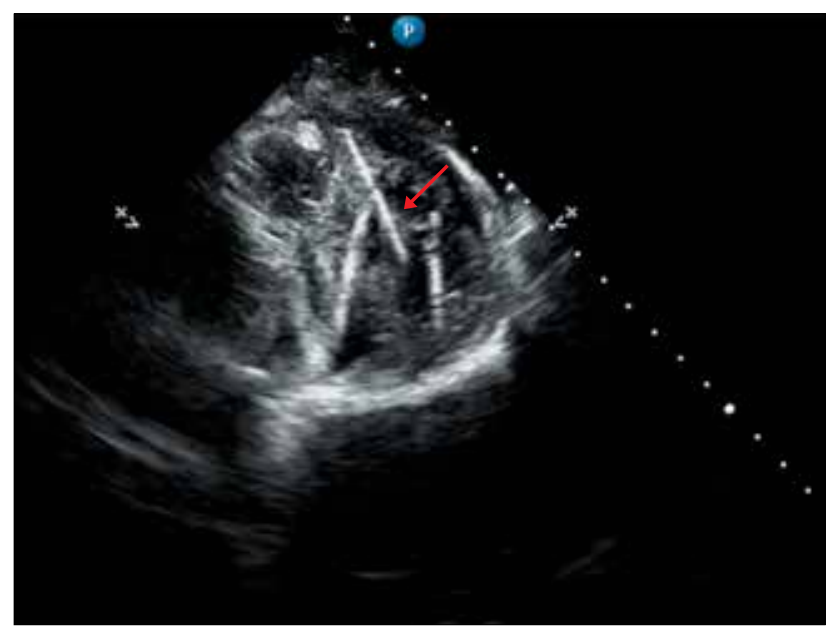

Fig. 2. Echocardiogram. Note echogenic, linear foreign bodies (arrow).

A computed tomography scan with contrast enhancement was performed (Fig. 3). Although there was evidence of interference, the scan showed the presence and position of the foreign bodies. 


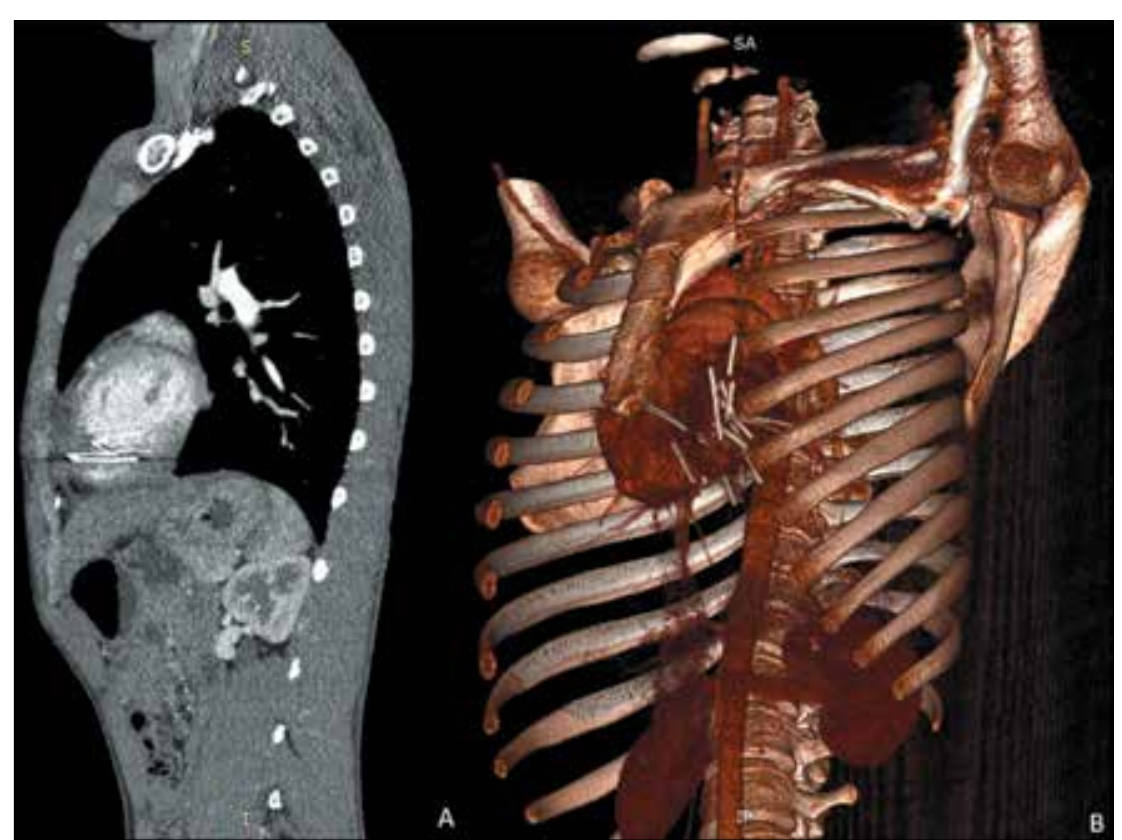

Fig. 3. Computed tomography scan, sagittal section $(A)$ and $3 D$ reconstruction (B).

The patient denied any knowledge of how, or perhaps even why, the needles were lodged within his heart. Although many hypotheses remain, no single theory can completely explain this phenomenon.

\section{Discussion}

The finding of a sewing needle (or multiple needles, in some instances) in the mediaan emergency department with acute-onset, sharp chest pain. Chest radiographs revealed 12 sewing needles, some of which were visi- ble within the cardiac silhouette. He required urgent surgery and was discharged within 15 days of hospitalisation.

Reported cases in the SA context are limited. One case reported by Sobnach et al. ${ }^{[3]}$ involved an SA patient, with the striking difference being the mechanism of injury, which involved ingestion of the sewing needles with subsequent migration, as opposed to the transthoracic route in our patient. Their patient made a full recovery after a median sternotomy to remove the needles. ${ }^{[3]}$

Ours was a unique case that will require a complex approach to management, but was easily diagnosed by simple chest radiography. The case is a good example of the importance of being vigilant when encountering abnormal presentations of common complaints.

A follow-up report will be compiled and submitted for publication after our patient has been fully evaluated and managed by the cardiothoracic surgeons.

\footnotetext{
1. Actis Dato GM, Arslanian A, di Marzio P, Filosso PL, Ruffini E. Posttraumatic and iatrogenic foreign bodies in the heart: Report of fourteen cases and review of the literature. J Thorac Cardiovasc Surg 2003;126(2):408-414. DOI:10.1016/S00225223(03)00399-4

2. Hermoni Y, Engel PJ, Gallant TE. Sequelae of injury to the heart caused by multiple needles. J Am Coll Cardiol 1986;8(5):12261231. DOI:10.1016/S0735-1097(86)80405-3

3. Sobnach S, Castillo F, Blanco Vinent R, Kahn D, Bhyat A. Penetrating cardiac injury following sewing needle ingestion. Heart Penetrating cardiac injury following sewing needle ingestion.
Lung Circ 2011;20(7):479-481. DOI:10.1016/.hlc.2011.01.006
} 